\title{
A
}

\section{Effect of ZnO Buffer Layers on the Crystallization of ITO Thin Film at Low Temperature}

\author{
Chung-Heon Seong ${ }^{\dagger}$, Yong-Jun Shin, and Gun-Eik Jang \\ Department of Advanced Materials Engineering, Chungbuk National University, Cheongju 361-763, Korea
}

Received June 14, 2012; Revised June 21, 2012; Accepted July 16, 2012

\begin{abstract}
In the present study, a ZnO thin film, as a buffer layer of ITO (indium tin oxide) film was deposited on glass substrates by RF magnetron sputtering at low temperature of $150^{\circ} \mathrm{C}$. In order to estimate the optical characteristics and compare with the experimental results in Glass/ZnO $(100 \mathrm{~nm}) / \mathrm{ITO}(35 \mathrm{~nm})$ multilayered film, the simulation program, EMP (Essential Macleod Program) was adopted. The sheet resistance and optical transmittance of the films were measured using the four-point probe method and spectrophotometer, respectively. From X-ray diffraction patterns, all the films deposited at $150^{\circ} \mathrm{C}$ demonstrated only the amorphous phase. Optical transmittance was the highest at a $\mathrm{ZnO}$ thickness of $100 \mathrm{~nm}$. The ITO $(35 \mathrm{~nm}) / \mathrm{ZnO}(100 \mathrm{~nm})$ film exhibits an optical transmittance of $>92 \%$ at $550 \mathrm{~nm}$. The multilayered film showed an electrical sheet resistance of $407 \Omega$ /sq., which is significantly better than that of a singlelayer ITO film without a $\mathrm{ZnO}$ buffer layer $(815 \Omega /$ sq.).
\end{abstract}

Keywords: TCO, ITO, ZnO, EMP, Buffer layer

\section{INTRODUCTION}

Transparent conductive oxide (TCO) layers play a very important role in today's optoelectronic devices such as liquid crystal displays (LCDs), organic light emitting devices (OLEDs) and plasma display panels (PDPs). Among the most widely used TCO materials, tin-doped indium oxide thin films have drawn significant attention because of their well-known physical properties such as low resistivity and high transmittance in the visible wavelength region [1,5-7]. In order to grow high-quality ITO film, various deposition processes have been reported, including the RF/DC magnetron sputtering, chemical vapor deposition (CVD) and pulsed laser deposition (PLD) methods [9-13]. Among the technologies available for ITO thin film production, magnetron sputtering has the advantage of being able to produce films with good quality [8]. In addition, the sputtering technique is frequently used due to its good reproducibility, high deposition rate and good adhesion of the coatings to the substrate [3]. Recently,

${ }^{\dagger}$ Author to whom all correspondence should be addressed: E-mail: schkingka@nate.com

Copyright $@ 2012$ KIEEME. All rights reserved.

This is an open-access article distributed under the terms of the Creative Commons Atribution Non-Commercial
License (httr:///creativecommons org/licenses/by-nc/3 0 ) which permits unrestricted noncommercial use, License (hitp:///ceativecommons.org/licenses/lby-nc/3.0) which permits unrestricted
distribution, and reproduction in any medium, provided the original work is properly cited. the preparation of high quality ITO films on plastic substrates is in great demand regarding applications for flexible display devices. However, characteristic properties of the film on polymer substrates are not easy to improve since the substrate heating is limited due to weak thermal resistance [5].

In this study, initially ZnO film as a buffer layer was deposited on glass substrate prior to ITO film deposition in order to improve crystallinity and film property of ITO and then subsequent deposition of ITO film was made on $\mathrm{ZnO}$ /glass by RF magnetron sputtering at $150^{\circ} \mathrm{C}$. The structural, electrical and optical properties of Glass/ZnO/ITO film were systematically investigated in term of different film thickness regarding the $\mathrm{ZnO}$ buffer layer. In order to estimate and compare with the experimental results, the simulation program, the Essential Macleod program (EMP), was adopted.

\section{EXPERIMENTAL}

ITO and $\mathrm{ZnO}$ thin films were prepared by RF magnetron sputtering at $150^{\circ} \mathrm{C}$. The compositions of the ITO target consisted of 90 wt.\% $\mathrm{In}_{2} \mathrm{O}_{3}$ and $10 \mathrm{wt} . \% \mathrm{SnO}_{2}$. The $\mathrm{ZnO}$ film was deposited on glass substrate at a sputtering thickness ranging from 0 to $125 \mathrm{~nm}$. Subsequently, the ITO film was deposited at sputtering 
Table 1. Deposition parameters for $\mathrm{ZnO}$ buffer and ITO film by RF magnetron sputtering.

\begin{tabular}{ccc}
\hline Deposition parameter & \multicolumn{2}{c}{ Sputtering condition } \\
\hline Target & $\mathrm{ITO}\left(\mathrm{In}_{2} \mathrm{O}_{3}: \mathrm{SnO}_{2}=90: 10 \mathrm{wt} \%\right)$ & $\mathrm{ZnO}(99.99 \%)$ \\
Base pressure & $2.5 \times 10^{-5}$ torr & $2.5 \times 10^{-5}$ torr \\
Working pressure & $2.5 \times 10^{-3}$ torr & $2.5 \times 10^{-3}$ torr \\
Substrate & $\mathrm{Glass}$ & $\mathrm{Glass}$ \\
Substrate temperature & $150^{\circ} \mathrm{C}$ & $150^{\circ} \mathrm{C}$ \\
RF Power & $100 \mathrm{~W}$ & $100 \mathrm{~W}$ \\
Working gas & $\mathrm{Ar} 40 \mathrm{sccm}$ & $\mathrm{Ar} 40 \mathrm{sccm}$ \\
\hline
\end{tabular}

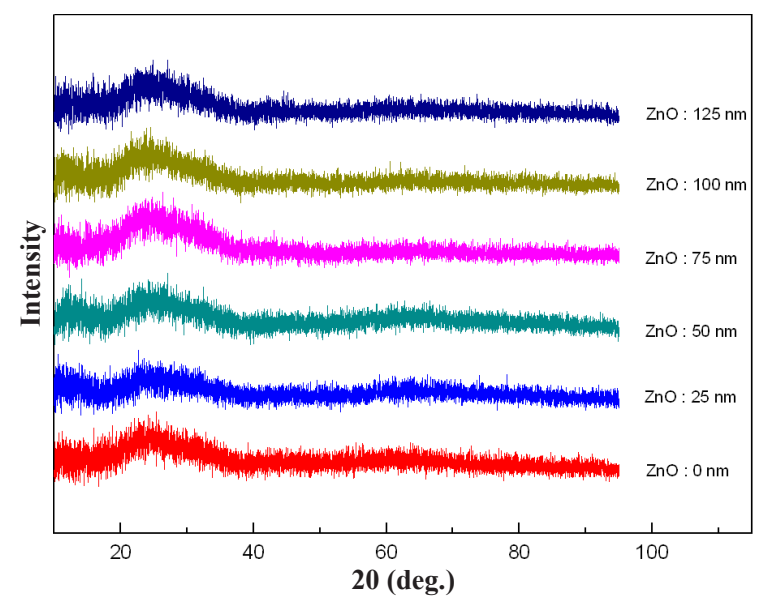

Fig. 1. XRD patterns of ITO films deposited on glass substrate at different $\mathrm{ZnO}$ film thicknesses.

thickness of $35 \mathrm{~nm}$. The sputtering chamber was evacuated to $2.5 \times 10^{-5}$ Torr before sputtering. The pressure during deposition was $2.5 \times 10^{-3}$ Torr. Mass flow controlled pure argon (99.999\%) was delivered to the chamber at a flux of $40 \mathrm{sccm}$. The substrate to target distance was $8 \mathrm{~cm}$. The RF power was set to $100 \mathrm{~W}$. Prior to deposition, the target was pre-sputtered for $15 \mathrm{~min}$ in order to remove any contamination. The deposition conditions of the samples are shown in Table 1.

For optical characterization, the EMP was adopted and the calculated results were compared with measured optical properties [4]. The simulation with variable parameters such as wavelength (400-700 nm) and thickness of layers [Glass/ZnO/ITO] was designed.

The thickness of the ITO layer was fixed at $35 \mathrm{~nm}$ and that of the $\mathrm{ZnO}$ buffer layer was varied between 0 and $125 \mathrm{~nm}$, as determined by the Alpha-step. The crystal structure of the films was analyzed by X-ray diffraction. The electrical properties of the films were obtained using a four-point probe method. The optical transmission spectra were measured in the wavelength ranging from $400-700 \mathrm{~nm}$ by a spectrophotometer. In addition, the interfacial properties of the optimized Glass/ $\mathrm{ZnO}(100 \mathrm{~nm}) /$ ITO(35 nm) electrodes were analyzed using AES depth profiling.

\section{RESULTS AND DISCUSSION}

Figure 1 shows XRD patterns of the ITO film and ZnO buffer layers deposited with various $\mathrm{ZnO}$ thicknesses (0, 25, 50, 75, 100, $125 \mathrm{~nm})$ at $150^{\circ} \mathrm{C}$. All the films deposited at $150^{\circ} \mathrm{C}$ showed that no characteristic diffraction peak of ITO was identified and only the amorphous nature of glass substrate was observed. It is believed that all films were shown to be amorphous because their grain

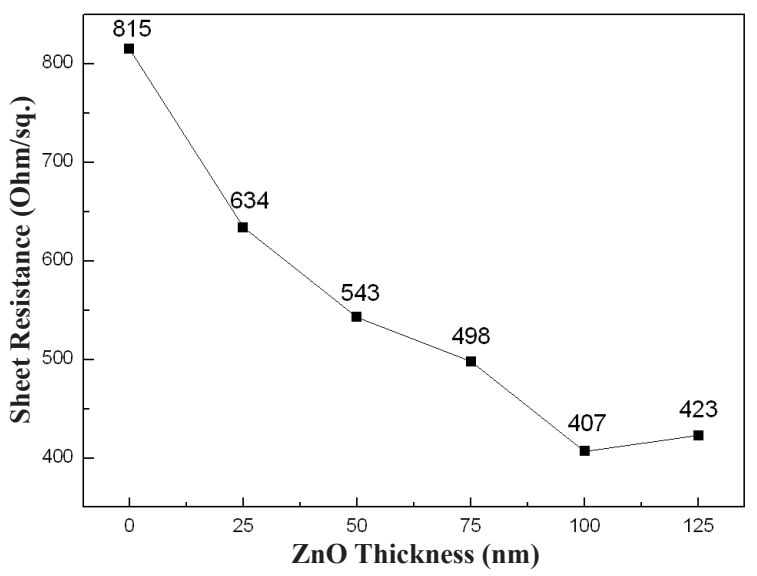

Fig. 2. Sheet resistances of ITO thin films with different film thickness of the $\mathrm{ZnO}$ buffer layer.

sizes were too small to detect the characteristic diffraction peak by the X-ray diffraction (XRD) method.

Figure 2 shows the sheet resistance of the ITO films deposited at $150^{\circ} \mathrm{C}$. The sheet resistance of single ITO film with a thickness of $35 \mathrm{~nm}$ was approximately $815 \Omega /$ sq. because of the low substrate temperature. The sheet resistance of the ITO films decreased with increasing thickness of the $\mathrm{ZnO}$ buffer layer. However, ZnO buffer layers thicker than $100 \mathrm{~nm}$ resulted in an increase of sheet resistance. In the case of the ITO film, the lowest sheet resistance of $407 \Omega /$ sq. was obtained at a $\mathrm{ZnO}$ buffer layer thickness of $100 \mathrm{~nm}$. It is believed that the crystallinity of ITO was improved such as the characteristic properties due to the insertion of the $\mathrm{ZnO}$ buffer layer.

Figure 3(a) shows the simulation results for the optical transmittance on the glass/ZnO/ITO multilayer film as a function of the $\mathrm{ZnO}$ thickness. The optical simulation was carried out by means of an EMP. All ITO films had high transmittance $(>80 \%)$ in the visible light region. The multilayer film with the thickness of glass/ZnO(100 nm)/ITO(35 nm) exhibits the highest optical transmittance of $92 \%$ at $550 \mathrm{~nm}$. The transmittance of glass/ $\mathrm{ZnO} / \mathrm{ITO}$ multilayer films was higher than that of single layer ITO films.

Figure 3(b) shows the measured optical transmittance of the glass/ZnO/ITO multilayer films as a function of the $\mathrm{ZnO}$ thickness. Similar to the simulated optical transmittance result, the transmittance spectra have shown that all films exhibit high transmittance $(>80 \%)$ in the $400-700 \mathrm{~nm}$ range. The multilayer film with the thickness of glass/ZnO(100 nm)/ITO(35 nm) exhibits the highest optical transmittance of $92 \%$ at $550 \mathrm{~nm}$. The transmittance of glass/ZnO/ITO multilayer films was higher than that of single layer ITO films. It is believed that the transmittance was increased with the increasing film adhesion property due to the insertion of the $\mathrm{ZnO}$ buffer layer.

In transparent conductor applications, electrical and optical coating parameter optimization plays a key role. Both conductivity and transmittance should be as high as possible for TCO applications. Hence the optimum value for these two parameters should be established using figure of merit. The most commonly used definition for figure of merit $\Phi_{\mathrm{TC}}$ regarding a transparent conducting film was first given by Haacke [2] as:

$$
\phi_{T C}=\frac{T_{r}^{10}}{R_{s h}}
$$

where $T_{r}^{10}$ is the transmittance at a particular wavelength and 

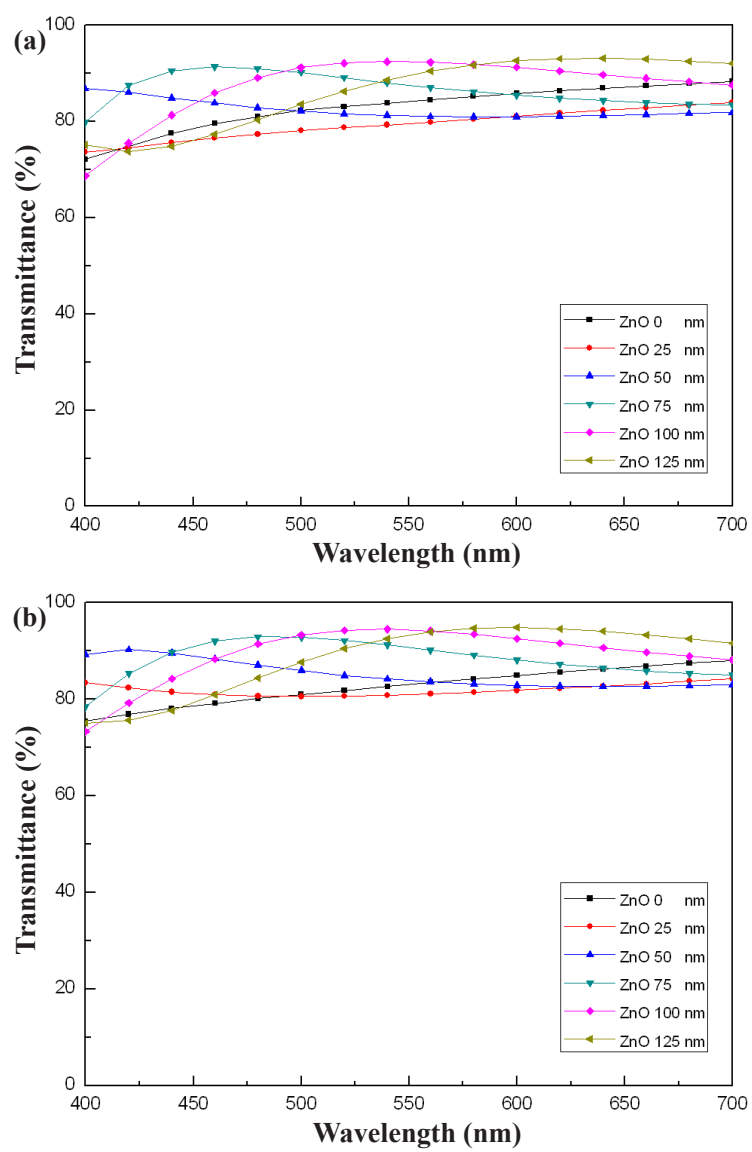

Fig. 3. (a) The simulated optical transmittance of the glass/ZnO/ITO multilayer films using EMP program and (b) the measured optical transmittance of the glass/ZnO/ITO multilayer films as a function of the $\mathrm{ZnO}$ thickness, respectively.

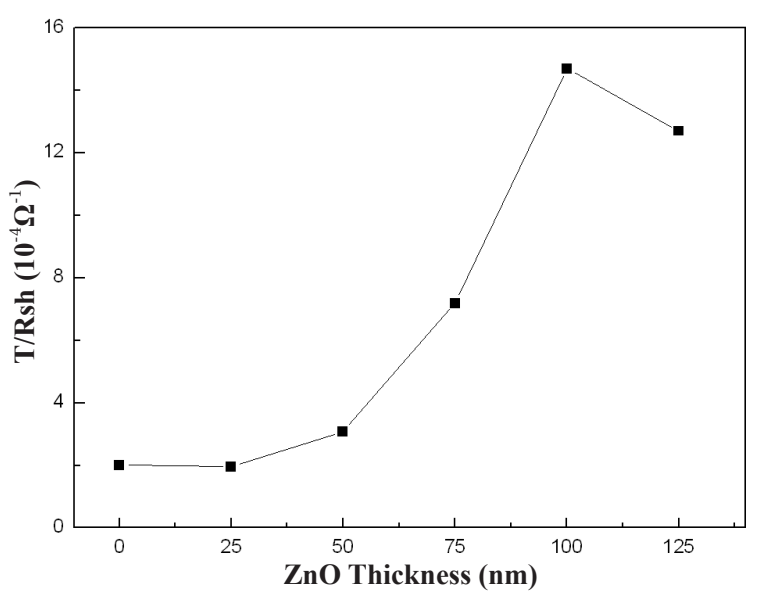

Fig. 4. Figure of merit for glass/ZnO/ITO multilayer film as a function of the $\mathrm{ZnO}$ thickness in the range of 0-125 nm.

$\mathrm{R}_{\mathrm{sh}}$ the sheet resistance. Figure 4 shows the calculated figure of merit $\left(\Phi_{\mathrm{TC}}\right)$. It was shown that the $\Phi_{\mathrm{TC}}$ value of the glass/ZnO/ITO multilayer film was increased from $2 \times 10^{-4} \Omega^{-1}$ to $14.7 \times 10^{-4} \Omega^{-1}$ by increasing the film thickness of the $\mathrm{ZnO}$ buffer layer. However, $\mathrm{ZnO}$ buffer layers thicker than $100 \mathrm{~nm}$ resulted in a decrease for figure of merit

Figure 5 shows the AES depth profiles of the optimized glass/

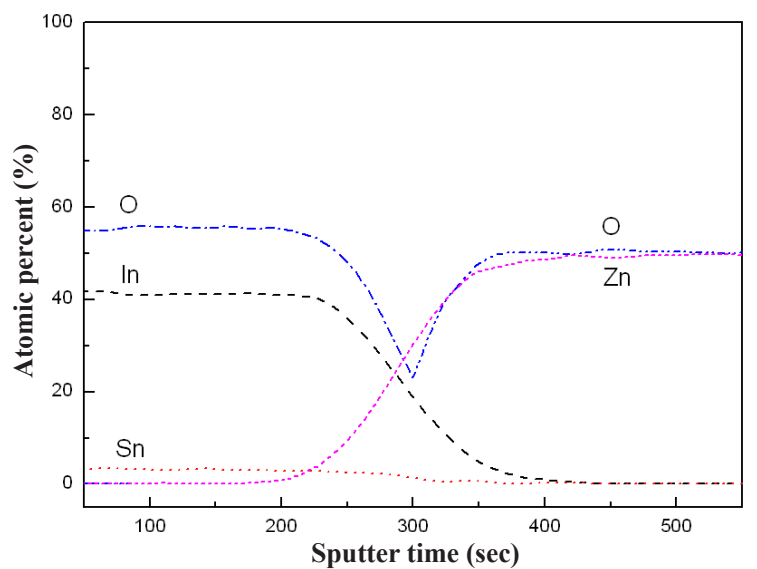

Fig. 5. AES depth profiles of glass/ZnO/ITO multilayer film grown on a glass substrate under an optimized condition.

$\mathrm{ZnO}(100 \mathrm{~nm}) / \mathrm{ITO}(35 \mathrm{~nm})$ electrodes on the glass substrate. Even the individual ITO and ZnO layers are well and clearly defined, some interdiffusion behavior can be observed between ITO film and the $\mathrm{ZnO}$ buffer layer.

\section{CONCLUSION}

ITO films were prepared on glass substrates using an RF magnetron sputtering method at $150^{\circ} \mathrm{C}$. According to XRD results, the structure of glass/ZnO/ITO multilayer film showing no characteristic diffraction peak of ITO was identified and only the amorphous nature of glass substrate was observed. However, the electrical and optical properties of ITO films were significantly improved through insertion of a $\mathrm{ZnO}$ buffer layer between the ITO film and glass substrate. The sheet resistance of the films decreased from $815 \Omega /$ sq. to $407 \Omega /$ sq. and optical transmittance increased from $82 \%$ to $92 \%$ at a wavelength of $550 \mathrm{~nm}$ when a $100 \mathrm{~nm} \mathrm{ZnO} \mathrm{buffer} \mathrm{layer} \mathrm{was} \mathrm{deposited.} \mathrm{We} \mathrm{believe} \mathrm{glass/ZnO/}$ ITO multilayer film showed satisfactory properties for applications such as transparent conducting electrodes.

\section{REFERENCES}

[1] B. H. Lee, I.G. Kim, S. W. Cho, S.H. Lee, Thin Solid films 302, 25(1997) [DOI: dx.doi.org/10.1016/S0040-6090(96)09581-8].

[2] C. Haacke, J. Appl. Phys. 47, 4086-4089(1976) [DOI: dx.doi. org/10.1063/1.323240].

[3] M. G. Zebaze Kana, E. Centurioni, D. Iencinella, C. Summonte, Thin Solid Films 500(2006) [DOI: dx.doi.org/10.1016/ j.tsf.2005.10.068].

[4] Y. S. Park, K. H. Choi, H.K. Kim, J. Phys. D Appl. Phys. 42, 235109(2009) [DOI: dx.doi.org/10.1088/00223727/42/23/235109].

[5] H. Kim, A. Pique, J.S. Horwitz, H. Mattoussi, H. Murata, Z. H. Kafafi, D. B. Chrisey, Appl. Phys. Lett. 79, 284(2001) [DOI: dx.doi.org/10.1080/000164801300043866].

[6] G. Haacke, Annu. Rev. Mater. Sci. 7, 73(1977).

[7] C. G. Granqvist, Appl. Phys. A. Mater. Sci. Process. 52, 83(1991) [DOI: dx.doi.org/ 10.1007/BF00323721].

[8] P. Thilakan, D. Minarini, S. Loreti, E. Terzini, Thin Solid Films 388(2001) [DOI: dx.doi.org/10.1016/S0040-6090(01)00820-3].

[9] J.H. Lee, B.O. Park, Transparent conducting $\mathrm{ZnO}$ : Al, In and Sn thin films deposited by the sol-gel method, Thin Solid Films 426, 94-99(2003) [DOI: dx.doi.org/10.1016/S0040- 
6090(03)00014-2]

[10] M. Jung, J. Lee, S. Park, H.J. Chang, Investigation of the annealing effects on the structural and optical properties of sputtered ZnO thin films, J. Cryst. Growth 283, 384-389(2005) [DOI: dx.doi.org/10.1016/j.jcrysgro.2005.06.047].

[11] O. Haga, T. Suzuki, Y. Kashiwaba, H. Watanabe, H. P. Zhang, Y. Segawa, High- quality ZnO films prepared on Si wafers by lowpressure MO-CVDK, Thin Solid Films 433, 131-134(2005) [DOI: dx.doi.org/10.1292/jvms.65.633].
[12] J. L. Zhao, X. M. Li, J. M. Bian, W. D. Yu, X. D. Gao, Structural, optical and electrical properties of $\mathrm{ZnO}$ films grown by pulsed laser deposition (PLD), J. Cryst. Growth 276, 507-512(2005) [DOI: dx.doi.org/10.1016/j.jcrysgro.2004.11.407].

[13] P. Zu, Z. K. Tang, G. K. L. Wong, M. Kawasaki, A. Ohtomo, H. Koinuma, Y. Segawa, Ultraviolet spontaneous and stimulated emissions from $\mathrm{ZnO}$ micro crystallite thin films at room temperature, Solid State Commun. 103, 459-463(1997) [DOI: dx.doi. org/10.1016/S0038-1098(97)00216-0]. 